\title{
EFFECT OF SIGMA PHASE PRECIPITATION ON MECHANICAL BEHAVIOR AND PITTING CORROSION OF DUPLEX STAINLESS STEEL
}

\author{
Talha Berguiga ${ }^{1)^{*}}$, Zakaria Boumerzoug ${ }^{1)}$ \\ 1) LMSM, Department of Mechanical Engineering, University of Biskra, 07000, Algeria
}

Received: 08.10.2018

Accepted: 21.01.2019

${ }^{*}$ Corresponding author: e-mail: ber_talha@yahoo.fr Tel.: +213661858174 LMSM, Department of Mechanical Engineering, University of Biskra, 07000, Algeria

\begin{abstract}
The main purpose of this work is to investigate the pitting corrosion behavior of sigmatized duplex stainless steel (DSS) exposed to two different chloride environments: simulated seawater solution and produced water solution. Specimens taken from a commercial DSS (UNS 31803) have been subjected to aging treatments at $850^{\circ} \mathrm{C}$ for different holding times to achieve different amounts of sigma phase. Metallographic examinations combined with X-ray diffraction technique were employed to follow the microstructure evolution. The pitting potential of the aged samples were determined in simulated seawater solution and produced water solution. It was established that solution treated DSS shows a high pitting corrosion resistance in both test solutions, while serious deterioration of corrosion properties occurs in presence of sigma phase. It was concluded that both sigma phase amount and chloride concentration worsen the pitting potential, the higher sigma content, the lower pitting potential and the higher chloride concentration, the lower pitting potential. SEM observation showed that pitting nucleation occurs preferentially at sigma phase interfaces due to the development of $\mathrm{Cr}$ - and Mo-depleted regions around sigma phase. It was also confirmed that the hardness behavior is only affected for long term aged samples.
\end{abstract}

Keywords: Duplex Stainless Steels (DSS), Sigma, Pitting Corrosion, Simulated Seawater, Produced Water

\section{Introduction}

Duplex stainless steels (DSS) are Fe-Cr-Ni alloys having an approximately volumetric fraction of $50 \%$ ferrite and $50 \%$ austenite in their microstructures [1]. DSS combine some characteristics of each of these phases. They have been introduced into the market during 1930s; since that time there has been an accentuated development and rapid spreading of their use [2]. They have been widely used in various industrial sectors due to their higher strength, better weldability, and higher resistance to stress corrosion and pitting [3]. Hence, DSS are attractive material for applications where these properties are desired like in off-shore industries, food industries, chemical industries, paper industries, nuclear industries and in structural applications as well $[4,5]$. In particular, the UNS S31803 alloy (also known as steel SAF 2205) is the most widely employed duplex stainless steels nowadays [6,7]. This material grade found widespread use in oil and gas industry, especially for high chloride containing process fluids like oily produced water and injection process systems. The superior properties of the duplex stainless steels come primarily from approximately equivalent amounts of austenite $(\gamma)$ and $\delta$-ferrite [3].

However, the use of DSS at high temperature is a typical concern to users of duplex stainless steels owing to their susceptibility to the formation of dangerous intermetallic phases, such as $\sigma-$ 
and $\chi$-phase, which form after ageing the material in a temperature range over $600{ }^{\circ} \mathrm{C}$ [8].Therefore, the use of duplex stainless steels has been usually limited to temperatures not exceeding approximately $500{ }^{\circ} \mathrm{C}$ [2]. For instance, according to ASME B31.3 Process Piping Code, the limit of use of UNS31803 Duplex stainless steel grade is $315^{\circ} \mathrm{C}$ [9].

It is supposed that among intermetallic precipitates, Sigma phase is the most detrimental one, as it causes a considerable drop in toughness as well as corrosion resistance [10]. Even small amounts of sigma phase influence the resistance against most corrosion forms such as pitting, sulfide stress corrosion cracking, intergranular corrosion and hydrogen embrittlement. Consequently, the standard criterion is that no sigma phase is allowed in produced duplex materials [11]. Sigma phase is a Cr-Mo rich hard precipitate which occurs at temperatures between $600-1000^{\circ} \mathrm{C}[4,12]$. The fastest sigma phase precipitation kinetics occurs at $850^{\circ} \mathrm{C}$. Once sigma phase is introduced in the microstructure it is difficult to recover the optimum microstructure [13]. The detrimental effect of sigma phase on corrosion resistance was usually associated to the formation of $\mathrm{Cr}$ - Mo depleted regions adjacent to sigma phase as a consequence of the eutectoid mechanism generating sigma phase. Concentration can fall below the minimum $12 \mathrm{wt}$. \% to $13 \mathrm{wt} . \%$ of chromium required to ensure the passivation process. Regions with quantities below the minimum $\mathrm{Cr}$ range undergo active dissolution and usually corrode at rates close to those of carbon steel and pure iron [14].

From a practical standpoint, sigma phase precipitation can be encountered during the welding process if the cooling rate from 1200 to $800^{\circ} \mathrm{C}$ is too slow. This usually occurs because either the heat input is too great or the interpass temperature is too high $[15,16]$. Incorrectly heat treated DSS may also suffer from sigma phase precipitation. Even though strict specifications and qualification tests are usually required for such grades, the delivery of stigmatized duplex stainless steel components still occurs at times [11].Recently, it was reported that there have been a large number of sigmatized DSS fittings that were delivered and installed in several projects related to offshore production facilities [11].

Numerous studies have been published about the impact of sigma phase on the corrosion resistance. However, most of the available studies have been conducted using a various electrochemical tests in chloride containing solutions $\left(\mathrm{NaCl}, \mathrm{CaCl}_{2}, ..\right)$. On the other hand there is no published studies examining the electrochemical behavior of sigmatized DSS when exposed to oil and gas field environment. There have been only a limited number of studies related to Super Duplex stainless steel (SDSS) materials tested in a simulated oil field environment [13]. Also the amount of literature on the seawater pitting of aged DSS is limited, more specifically in term of correlation between sigma phase content and pitting potential values.

Given the above facts, this research work was mainly conducted to investigate the pitting corrosion behavior of sigmatized DSS exposed to two different chloride containing environments: simulated seawater solution and produced water solution. It is expected from this study to show the relationship between sigma phase content and pitting potential values. The sigmatized samples were obtained by aging treatment at $850^{\circ} \mathrm{C}$ during various holding times to introduce varied levels of sigma phase. Therefore, as part of this study, the microstructural evolution after ageing and the effect of sigma phase on the hardness behaviour were also investigated.

\section{Materials and experimental procedure}

The investigated steel grade in this study is a duplex stainless steel (ASTM 790 UNS 31803) received in the solution treated condition, as a seamless pipe with 3 inch diameter and $5.5 \mathrm{~mm}$ thickness. The chemical composition of this pipe is given in Table $\mathbf{1}$. 
Table 1 Chemical composition of the studied Material

\begin{tabular}{|c|c|c|c|c|c|c|c|c|c|}
\hline Elements & $\mathbf{C}$ & $\mathbf{S i}$ & $\mathbf{M n}$ & $\mathbf{P}$ & $\mathbf{S}$ & $\mathbf{C r}$ & $\mathbf{M o}$ & $\mathbf{N i}$ & $\mathbf{N}$ \\
\hline wt. (\%) & 0.013 & 0.550 & 1.100 & 0.0260 & 0.0006 & 22.400 & 3.150 & 5.450 & 0.1850 \\
\hline
\end{tabular}

Specimens of approximately $20 \mathrm{~mm}$ length and $10 \mathrm{~mm}$ wide were obtained. A number of samples were kept without any treatment as reference, and the rest of specimens were isothermally aged at $850^{\circ} \mathrm{C}$ for different holding times ranged from 5 minutes to 360 minutes, in a tubular electric furnace equipped with a temperature controller. At the end of each treatment the specimen was immediately water quenched in order to interrupt the phase transformation process. After heat treatment, the specimens were grinded and polished with alumina powder. Metallographic examinations have been carried out using electrolytic etching in oxalic acid under 2-2.5 $\mathrm{V}$ during 10 to 20 seconds [17]. This procedure has the advantage to allow quantitative metallographic analysis of sigma phase. The electrolytic etching employed colors the phases as follows: ferrite-gray, austenite - white, and sigma phase - dark. In addition, the presence of different phases in the specimens was also identified by X-ray diffraction analysis (XRD). Complementary microstructural characterizations using scanning electron microscope (SEM) operated from 7.0 to $30 \mathrm{kV}$ have been used for a number of aged samples for further confirmations purpose. The susceptibility of the aged DSS to pitting corrosion was evaluated by potentiodynamic polarization tests. The experiments were conducted in two different chloride solutions: Produced Water solution and $0.5 \mathrm{M} \mathrm{NaCl}$ solution simulating seawater chloride concentration. Tests solutions were exposed to laboratory air at room temperature (approximately $25^{\circ} \mathrm{C}$ ). Produced Water is the recovered water from crude oil production system after separation and filtration. Treated produced water is sent for reinjection into the oil reservoir to increase the oil recovery capacity. The chemical analysis of the produced water used as a test solution for this study is presented in Table 2.

Table 2 Chemical Analysis of Produced Water

\begin{tabular}{|l|c|c|c|c|c|}
\hline Elements & $\mathrm{Cl}^{-}$ & $\mathrm{HCO}_{3}^{-}$ & $\mathrm{Na}^{+}$ & $\mathrm{Ca}^{++}$ & $\mathrm{K}^{+}$ \\
\hline Concentration $(\mathrm{mg} / \mathrm{l})$ & 28862 & 61 & 30765 & 97 & 418 \\
\hline
\end{tabular}

The polarization tests were carried out using a potentiostat VOLTALAB PGZ-301 consisting of three electrodes. Platinum was used as the counter electrode and saturated calomel electrode (SCE)) was employed as the reference electrode. The specimens acting as working electrode were embedded in epoxy resin with an approximate exposure area of $1 \mathrm{~cm}^{2}$. Before each test, the exposed surfaces of samples were polished up to 4000 grit finish then rinsed with distillated water and dried in air. The potentiodynamic measurements were performed at a scan rate of $1 \mathrm{mV} / \mathrm{S}$ until an anodic current of $100 \mu \mathrm{A} / \mathrm{cm}^{2}$ was exceeded $[18,19]$. The pitting potential $\left(\mathrm{E}_{\mathrm{pit}}\right)$ was defined at the potential where the anodic current density exhibited a sharp and sustained increase from the background passive current density [6].

Tested samples in simulated seawater were numbered from "0-SW" to "360-SW" whilst the tested samples in produced water were numbered from "0-PW" to "360-PW", where the numeric characters denote the aging time in minutes. Based on that, specimen identification adopted in this work are listed in Table 3. After the polarization tests, the surface of the pitted samples were cleaned and analyzed using SEM observation to examine pit morphology and preferential location. 
In order to investigate the effect of microstructure evolution on hardness behavior of the studied material, Vickers microhardness measurements were performed using $0.3 \mathrm{~kg}$ load.

Table 3 Specimens identification

\begin{tabular}{|c|c|c|}
\hline Aging Time (min) & Test solution & Identification \\
\hline 0 (Solution annealed condition) & Simulated Seawater & $0-\mathrm{SW}$ \\
\hline 5 & & $5-\mathrm{SW}$ \\
\hline 30 & & $30-\mathrm{SW}$ \\
\hline 60 & & $60-\mathrm{SW}$ \\
\hline 360 & & $360-\mathrm{SW}$ \\
\hline 0 (Solution annealed condition) & Produced Water & $0-\mathrm{PW}$ \\
\hline 5 & & $5-\mathrm{PW}$ \\
\hline 30 & & $30-\mathrm{PW}$ \\
\hline 60 & & $60-\mathrm{PW}$ \\
\hline 360 & & $360-\mathrm{PW}$ \\
\hline
\end{tabular}

\section{Results And Discussions}

\subsection{Characterization of the investigated material at the as received condition}

The microstructure of the studied material in the as received condition is shown in Fig. 1, it contains solely austenite and ferrite; ferrite in gray and austenite in white. In addition, the presence of these phases was confirmed by X-ray diffraction analysis as shown in Fig. 2, no other phases or precipitates have been detected in the investigated DSS at the as received state.

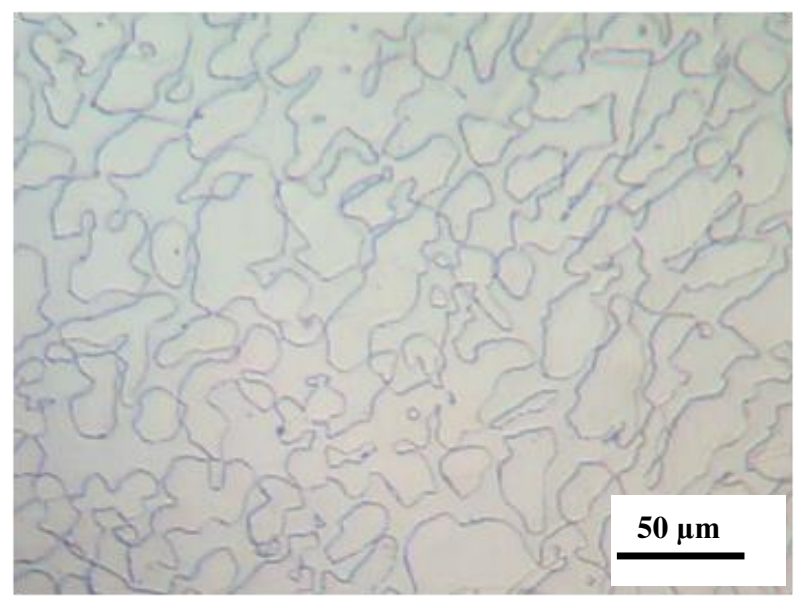

Fig. 1 Micrograph of the investigated metal at the as received state

The absence of precipitates in the matrix could be explained by the fact that the investigated material was successfully solution treated as required by the manufacturing standard governing the DSS used in this study [20]. 


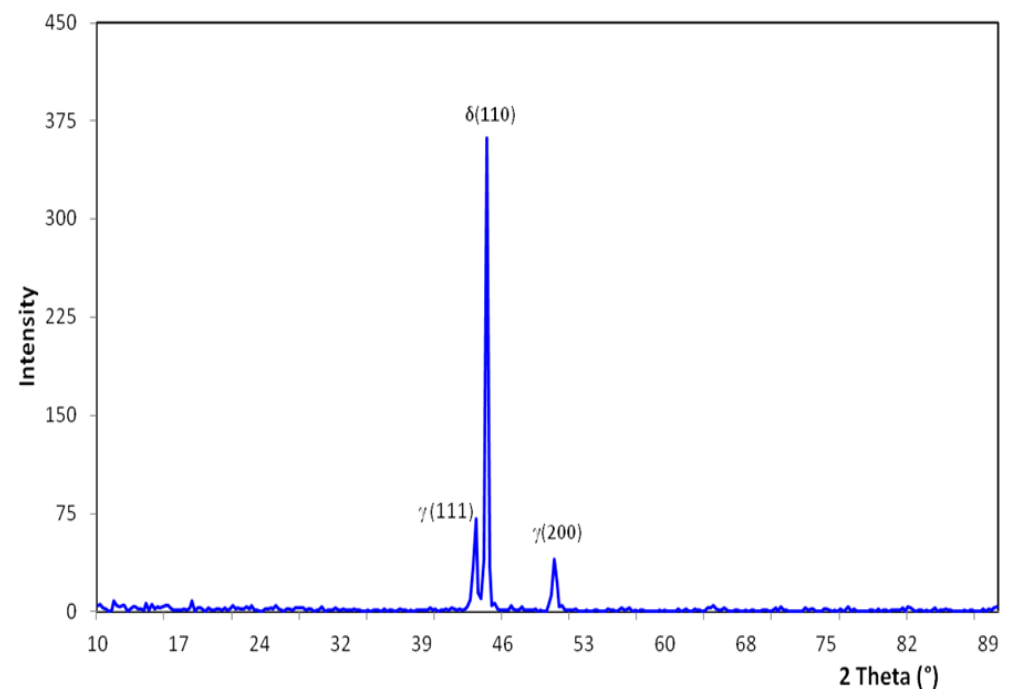

Fig. 2 X-Ray diffraction pattern of the studied material in the as received condition

\subsection{Sigma $(\sigma)$ phase characterization and formation mechanism after aging treatments at $850{ }^{\circ} \mathrm{C}$}

Fig. 3 shows the microstructure of the aged specimen at $850{ }^{\circ} \mathrm{C}$ for 5 minutes holding time. It is well noted that the precipitation of $(\sigma)$ sigma phase has been taken place in this treated specimen. Sigma $(\sigma)$ phase appears in dark color at the $\delta / \gamma$ boundaries. It should be noted that $\chi$ phase precipitates are also present in the matrix of this aged specimen. However, the volume fraction of $\chi$ was small in comparison with $\sigma$ phase and it had a far less influence on DSS than $\sigma$ phase did [21].

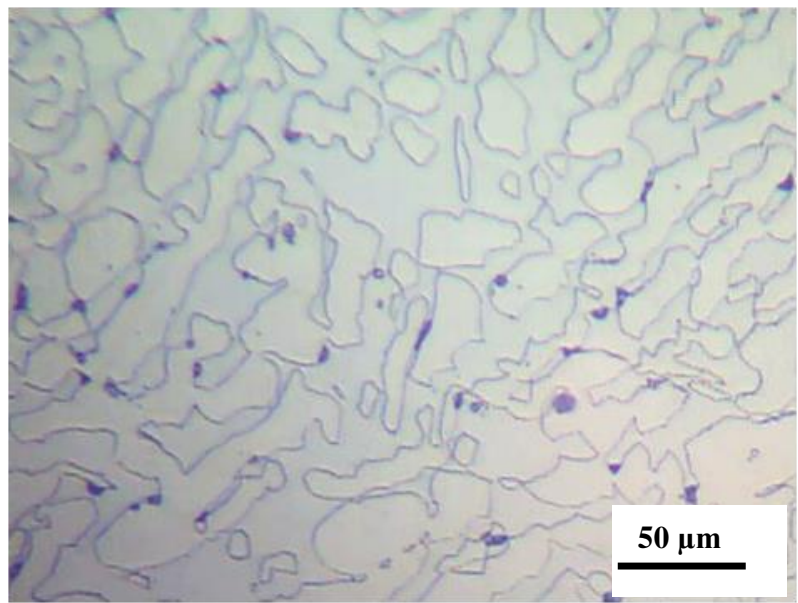

Fig. 3 Optical microstructure corresponding to the aged specimen at $850{ }^{\circ} \mathrm{C}$ for $5 \mathrm{~min}$

The evidence from transmission electron microscopy also suggests that $\chi$ phase is much more unstable than $\sigma$ phase and would eventually transform to $\sigma$ phase [3]. These findings and assumptions are also applicable for the other aged specimens in this work; therefore $\chi$ phase 
precipitation was not taken in charge in the present study. In fact, when the studied duplex stainless steel specimens were exposed to heat treatment at $850{ }^{\circ} \mathrm{C}$, the original austenite / ferrite balance was disturbed, causing the material to search for a more stable thermodynamic state through the precipitation of sigma phase. The precipitation of sigma phase proceeds according to the following eutectoid mechanism:

$\delta \rightarrow \gamma_{2}+\sigma$

where $\gamma_{2}$ is the so-called secondary austenite [21].

According to Fig. 3 sigma $(\sigma)$ phase nucleates preferentially at the $\delta / \gamma$ interfaces and grows through the adjacent ferrite grain; this feature is more visible on the aged specimens for longer periods as displayed in Fig. 4, which shows SEM image of heat treated sample at $850{ }^{\circ} \mathrm{C}$ for 360 min holding time.

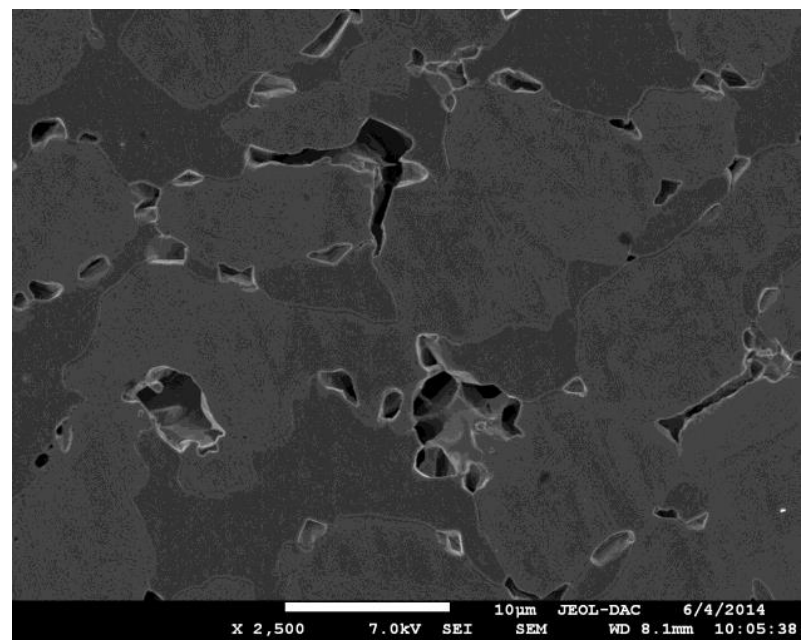

Fig. 4 SEM micrograph corresponding to the aged specimen at $850{ }^{\circ} \mathrm{C}$ for $360 \mathrm{~min}$

This is a typical feature for sigma phase precipitation in DSS, and it is due to the high interface energy of the $\delta / \gamma$ interphase boundary, and as many defects concentrate there, it is a beneficial site for the heterogeneous nucleation of the $\sigma$ phase $[17,22,23]$. When the $\sigma$ phase nucleates at the $\delta / \gamma$ interphase boundary, some defects disappear, which releases the free energy of the materials [24]. The noticeable fastest and the high susceptibility of sigma precipitation at $850{ }^{\circ} \mathrm{C}$ in the investigated material reported in this study is in good agreement with previous ones, especially the research work conducted by Palmer et al [25] using a synchrotron based in situ X-ray diffraction technique. It was pointed out that sigma $\sigma$ phase was first observed approximately 40 seconds after the start of the aging treatment at $850{ }^{\circ} \mathrm{C}$. The high susceptibility of the duplex stainless steels to the sigma phase formation is frequently attributed to the ferrite composition, richer in the sigma forming elements $(\mathrm{Cr}, \mathrm{Mo}$ and $\mathrm{Si}$ ) and poorer in the elements that are less soluble in sigma $(\mathrm{C}, \mathrm{N}$ and $\mathrm{Ni})$ than in austenite [17].

\subsection{Effect of holding time on sigma ( $\sigma$ ) evolution and quantitative analysis}

Fig. 5 presents the microstructures of the aged specimens at $850{ }^{\circ} \mathrm{C}$ for different holding periods. Sigma phase appears in dark color. It can be clearly seen that increasing the holding 
time at $850^{\circ} \mathrm{C}$ has the effect to increase the amount of $\sigma$ phase. It leads also to the coarsening increase of the $\sigma$ phase in an irregular shape. The estimated volume fraction of sigma phase by image analysis techniques in function of holding time was plotted in Fig. 6.

As it can been seen from Fig. 6, the volume fraction of sigma phase start from $1 \%$ for a holding time of $5 \mathrm{~min}$ to reach $11 \%$ after 360 min holding time.
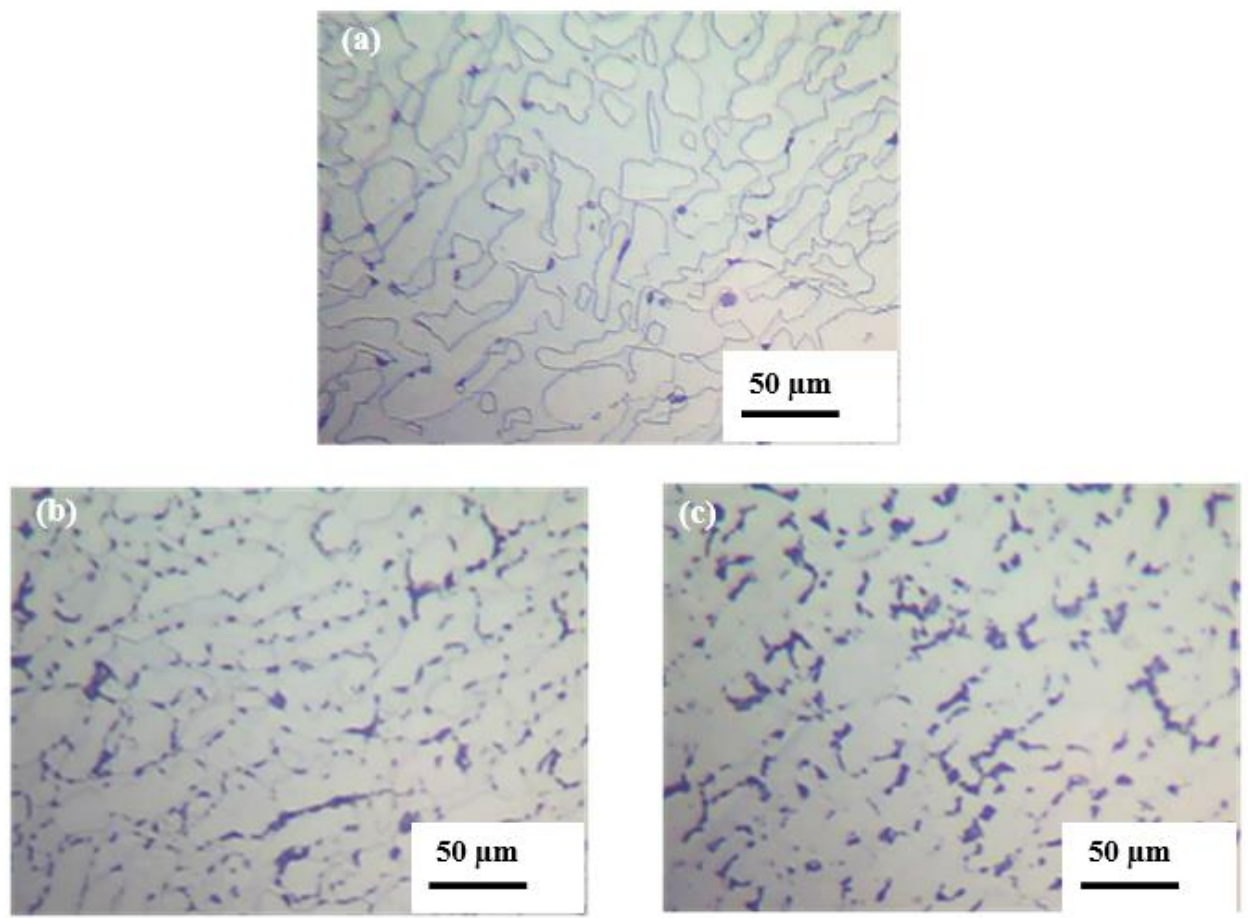

Fig. 5 Optical micrographs showing the aged specimens at $850^{\circ} \mathrm{C}$ for (a) $5 \mathrm{~min}$, (b) $60 \mathrm{~min}$ and (c) $360 \mathrm{~min}$

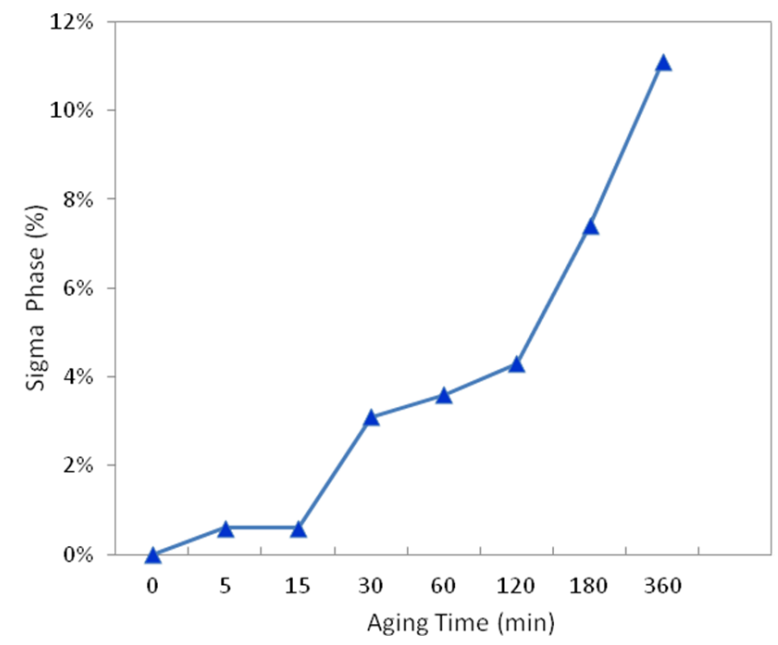

Fig. 6 Variation of the volume fraction of sigma phase in UNS S31803 as a function of aging time at $850{ }^{\circ} \mathrm{C}$ 
X-Ray Diffraction analysis has also confirmed this trend. As previously stated, the X-ray diffraction pattern of the solution treated specimen shows ferrite and austenite phase peaks only and does not show any peak corresponding to other phases, however small peaks corresponding to sigma phase have been observed on the aged specimens at $850{ }^{\circ} \mathrm{C}$, these peaks are more detectable in the aged sample for 360 min holding time as reported in Fig. 7. With increasing holding time, the intensity of sigma peaks increases and the peak intensity of the ferrite phase compared to the austenite phase decreases, this is directly linked with the decomposition process of ferrite into sigma phase and secondary austenite.

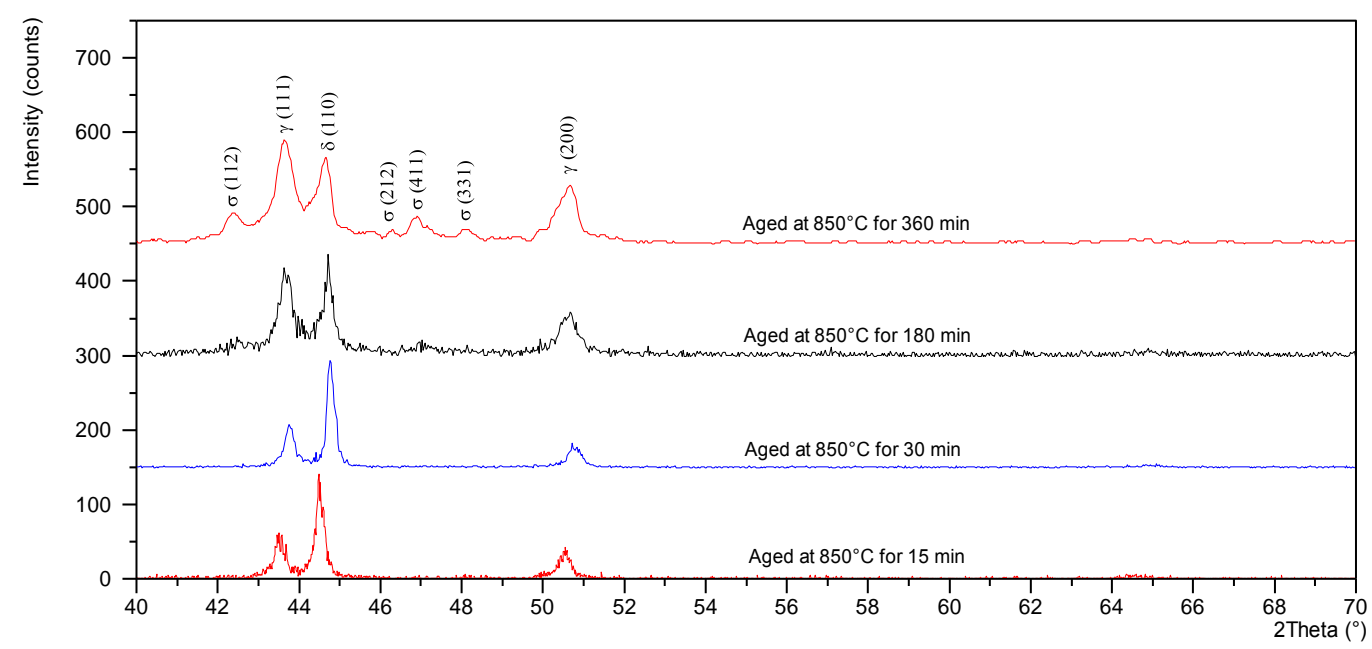

Fig. 7 X-Ray diffraction patterns of samples aged at $850^{\circ} \mathrm{C}$

Furthermore, the XRD pattern did not show the $\sigma$ phase signals in the specimens aged for 30 and 15 min, although there was evidence of its occurrence. This could be explained by the low fraction of the $\sigma$ phase [21]. Consequently, it can be concluded that all the obtained diffraction peaks are in good agreement with the changes in $\sigma$ phase ratio during the isothermal treatments.

\subsection{Influence of sigma phase on pitting potential}

Potentiodynamic polarization tests were conducted to evaluate the pitting susceptibility of aged DSS samples with different sigma content levels. Fig. 8 presents typical polarization curves conducted in $0.5 \mathrm{M} \mathrm{NaCl}$ solution.

Basing on the analysis of the polarization curves the pitting potential $\mathrm{E}_{\mathrm{pit}}$ values of the different tested samples were determined. The obtained values are shown in the Table 4.

Table 4 Pitting potentials for the tested samples in Simulated seawater

\begin{tabular}{|c|c|c|c|c|c|}
\hline Sample identification & 0-SW & 5-SW & 30-SW & $60-\mathrm{SW}$ & 360-SW \\
\hline Aging time (min) & 0 & 5 & 30 & 60 & 360 \\
\hline $\mathrm{E}_{\mathrm{pit}}(\mathrm{mV} / \mathrm{SCE})$ & 1120 & 980 & 910 & 790 & 560 \\
\hline
\end{tabular}




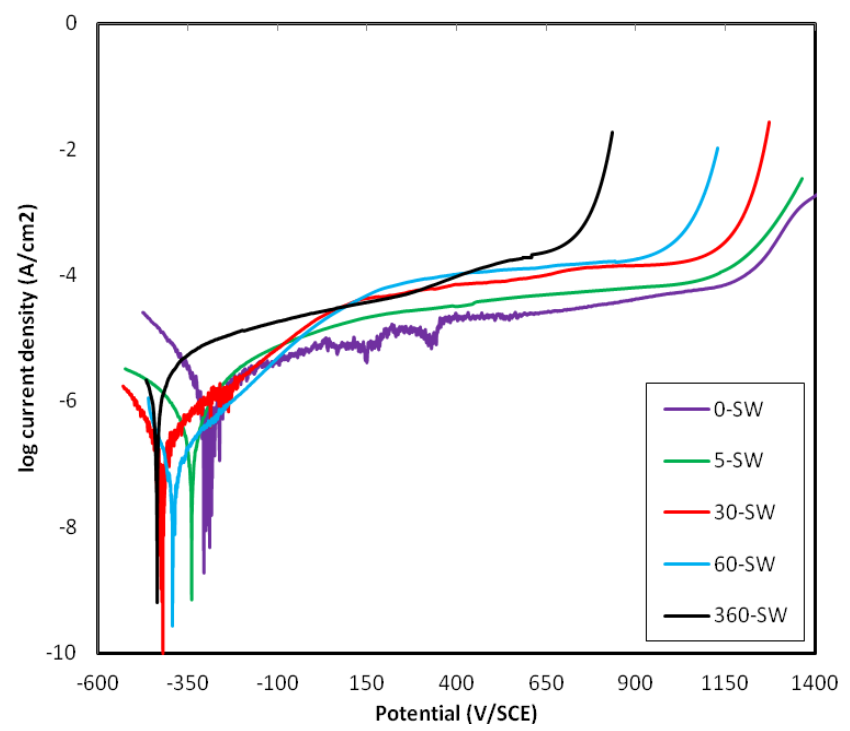

Fig. 8 Potentiodynamic polarization curves for the aged samples at $850{ }^{\circ} \mathrm{C}$ in for different times in simulated seawater solution

It can be seen from Table 4 that the pitting potentials of tested samples decrease markedly with increasing of aging time from $1120 \mathrm{mV}$ (SCE) of the solution treated sample to $560 \mathrm{mV}$ (SCE) of the aged for $360 \mathrm{~min}$. It was previously established in this research work that the increase of the aging time has the effect to increase the sigma phase ratio. So it's clear that the decrease of pitting corrosion resistance in the aged DSS samples is directly attributed to the formation of sigma phase and its volume fraction. Even about $3.1 \%$ of sigma phase which corresponds to the aged sample for 30 min can affect dramatically the pitting resistance of the alloy. On the other hand, the un-aged sample show the highest pitting potential value, supporting the standard recommendation of using DSS in the solution treated condition with no sigma phase content. Actually, it is well documented in the literature that the resistance of this material to localized corrosion is mainly due to the higher content of chromium and molybdenum which protect the DSS by forming and stabilizing the passive film. The decrease in pitting potential as a result of sigma phase formation has been explained by many authors, and it was related to chromium and molybdenum depletion in the zones surrounding sigma phase [6, 21, 26, 27]. During the formation of sigma phase, $\mathrm{Cr}$ and Mo diffused from the ferrite phase to the growing sigma phase, thus causing localized depletion areas in $\mathrm{Cr}$ and Mo around the sigma phase. These areas containing lower concentration of $\mathrm{Cr}$ and $\mathrm{Mo}$ and higher amount of $\mathrm{Ni}$ became unstable and transformed into secondary austenite [21]. These $\mathrm{Cr}$ - and Mo-depleted areas surrounding sigma phase become susceptible to pitting attack and thus a reduction on pitting potential is registered. The lower molybdenum and chromium content is not the only factor for being prone to corrosion. The neighborhood of the more noble phases will enhance the anodic dissolution of the new formed secondary austenite [28].

This behavior of decrease in corrosion resistance due to the increase in aging time was also established in the tested samples in Produced Water as outlined hereafter.

The polarization curves for the tested specimens in produced water solution are presented in Fig. 9. Following the same methodology adopted previously for the tested specimens in 
simulated seawater solution, the pitting potential values have been determined and listed in the Table 5. The presented data suggest that the pitting potential of the various tested samples show a clear dependence on the aging time. As expected, for high aging time, and consequently high sigma volume fraction, low pitting potential is registered. However, it is well noted that for same aging time a lower pitting potential is found for tested sample in produced water solution.

The lower corrosion resistance of aged DSS in produced water solution can be explained by the higher chloride content in this solution. The other chemical species of the produced water solution shown in Table 2 do not appear to have a significant impact on the pitting corrosion behavior. In fact the chloride concentration in the simulated seawater solution $(0.5 \mathrm{M} \mathrm{NaCl}$ solution) is about $17725 \mathrm{ppm}$ while in the produced water solution is about $28862 \mathrm{ppm}$. This confirms that the pitting potential depends on both sigma phase content and the chloride concentration. For chloride, three different models are frequently quoted to explain its effects on pitting: adsorption leading to local film dissolution, penetration of anions in the film leading to weakening of the oxide bonds, and rupture of film at defects, such as cracks and dislocations [18].

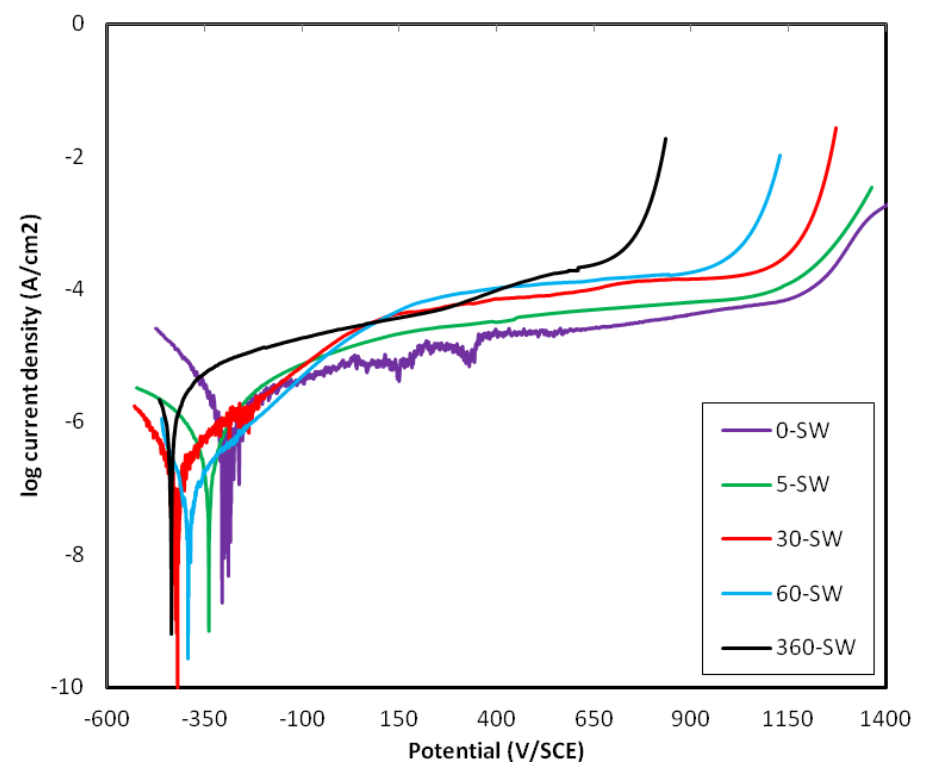

Fig. 9 Potentiodynamic polarization curves for the aged samples at $850^{\circ} \mathrm{C}$ in for different times in Produced Water solution

Table 5 Pitting potentials for the tested samples in Produced Water

\begin{tabular}{|l|c|c|c|c|c|}
\hline Sample identification & 0-PW & 5-PW & 30-PW & $60-\mathrm{PW}$ & 360-PW \\
\hline Aging time (min) & 0 & 5 & 30 & 60 & 360 \\
\hline $\mathrm{E}_{\mathrm{pit}}(\mathrm{mV} / \mathrm{SCE})$ & 1024 & 950 & 720 & 570 & 450 \\
\hline
\end{tabular}

On the other hand the obtained results suggest that the un-aged sample demonstrate an acceptable pitting resistance when exposed to produced water test solution, confirming the indication that this material grade when successfully heat treated is highly suitable for use for produced water process fluids, even at a high level of chloride concentration. Therefore, caution 
is needed by DSS manufacturers and users to ensure a high quality of DSS products during processing, machining, heat treatments and welding to avoid sigma phase formation.

\subsection{Pitting morphology \& its relation to sigma phase}

To understand the effect of aging on pits morphologies and the relation between sigma phase and pitting nucleation sites, the pitted samples have been analyzed using SEM observations with secondary electron image (SEI) and backscattered electron image (BEI). Fig. 10 displays the typical SEM images of pitied samples after polarization tests in simulated seawater solution. Small size isolated pits are observed in the solution treated sample while sever pitting corrosion is registered in the aged sample for $60 \mathrm{~min}$ with a larger size pits compared to the solution treated sample. In particular Fig. 10(d) presents a "lacy pattern pit morphology", similar to the observations made by other research groups [26, 27]. It is well observed also that pits initiated close to sigma phase regions which is an indication that pits nucleate preferentially at sigma phase interfaces. This finding can be explained by the fact that sigma phase precipitation could lead to the development of Cr- and Mo-depleted zones around the sigma phase, formed by secondary ferrite and by secondary austenite. Thus pit growth occurs as selective corrosion of the metallic matrix surrounding the sigma phase, which is explained by the presence of Cr- and Mo-depleted ferrite or austenite phases surrounding the sigma, as a consequence of the lower corrosion resistance of those secondary phases [26].

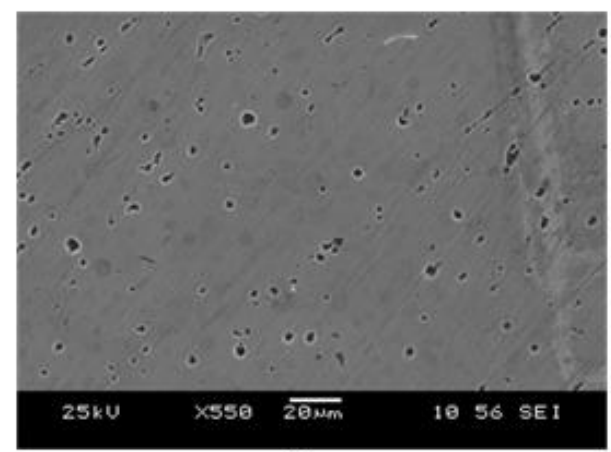

(a)

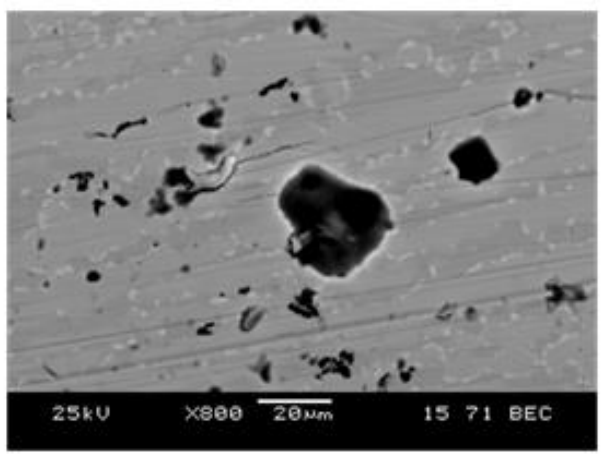

(c)

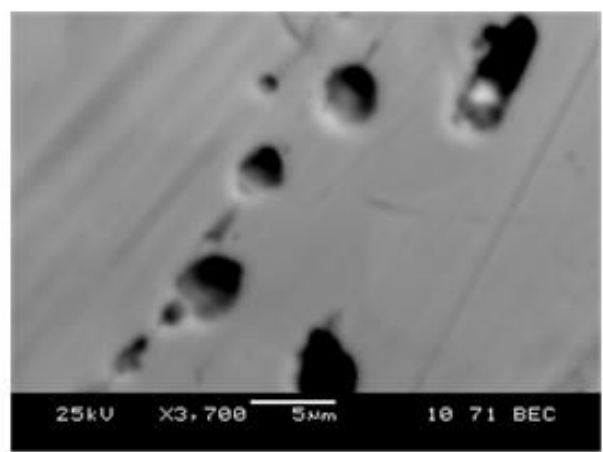

(b)

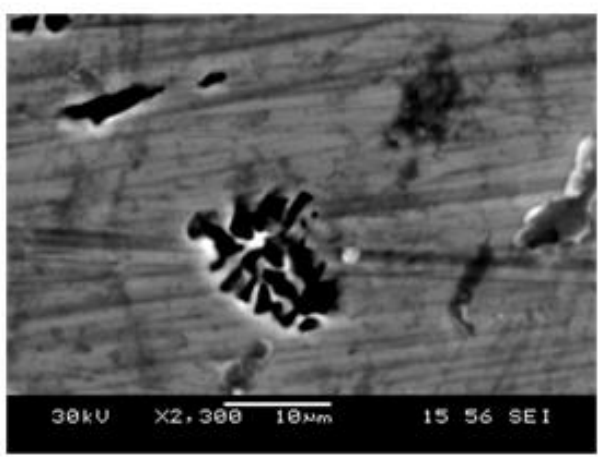

(d)

Fig. 10 SEM images of pitted samples (a) and (b) solution treated sample, (c) and (d) aged samples for $60 \mathrm{~min}$ at $850{ }^{\circ} \mathrm{C}$ 


\subsection{Impact of sigma phase on hardness}

The results of the hardness measurement of the treated samples are plotted on Fig. 11. The general trend observed in this figure stipulates that when the holding time is increased the hardness is increased consequently; this is due to sigma phase volume ratio present in the matrix of the aged samples. The higher sigma phase amount, the higher hardness value. In fact, the hardness of the $\sigma$ phase is significantly greater than that for the $\chi$ phase; ferrite or austenite [29], therefore the increase in the hardness is attributed to the increasing in concentration of the $\sigma$ phase. However, it was noted that short-term aging at $850{ }^{\circ} \mathrm{C}$ results in little decrease in hardness, compared to the hardness of the base material $(276 \mathrm{Hv})$. This slight reduction in hardness for short-term aged samples is probably associated to reduction in solute contain of ferrite to nucleate sigma phase, particularly reduction in chromium and molybdenum content [30]. But generally speaking it is well established that the hardness is not a sensitive measure for low sigma content as indicated by Nilsson et al [31].

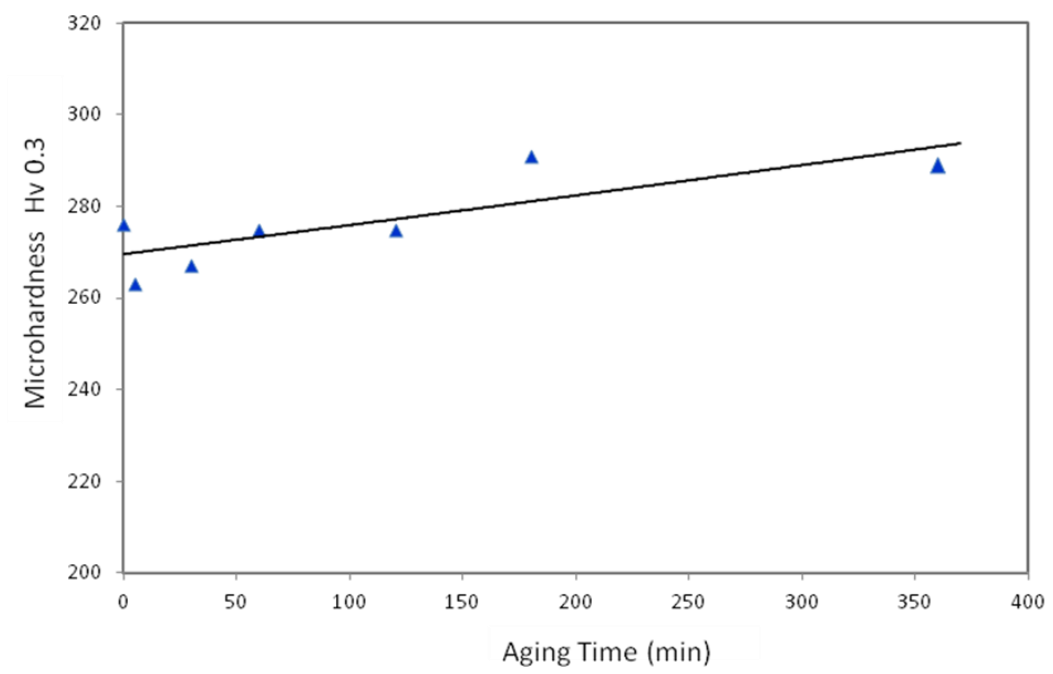

Fig. 11 Microhardness evolution as a function of aging time at $850^{\circ} \mathrm{C}$ for the studied DSS (UNS S31803)

\section{Conclusions}

In this work the sigma phase precipitation in UNS 31803 DSS during isothermal aging at $850 \mathrm{C}^{\circ}$ has been investigated. The effect of sigma phase on pitting corrosion resistance and hardness behavior was also studied. It constitutes a good background for understanding the quantitative correlation between sigma phase amount and corrosion resistance.

The principal conclusions that can be drawn from this work are the followings:

- The microstructure evolution of the aged material has been interpreted in terms of $(\sigma)$ sigma phase precipitation on the basis of image analysis and XRD. The obtained diffraction peaks are in good agreement with the analysis of metallographic images of aged DSS samples. The results show that the duplex stainless steel UNS31803 is very sensitive to the formation of sigma phase at $850^{\circ} \mathrm{C}$.

- The evidence shows that short-term aging at $850^{\circ} \mathrm{C}$ of UNS S31803 DSS leads to sigma phase precipitation following a preferential nucleation at ferrite / austenite interfaces. 
- Increasing the holding time at $850{ }^{\circ} \mathrm{C}$ has the effect to increase the volume fraction and particle size of $(\sigma)$ sigma phase. The higher holding time, the higher amount of $(\sigma)$ sigma phase.

- Solution treated DSS samples show a high pitting corrosion resistance in both test solutions, simulated sea water and produced water, making this material grade highly suitable for use in chloride containing environments. However, serious deterioration of corrosion properties occurs in presence of sigma phase which may be introduced into the DSS microstructure in most cases as a result of inappropriate heat treatment. The results show that even about $3.1 \%$ of sigma volume fraction is sufficient to cause a significant reduction on the pitting corrosion resistance of the UNS 31803 DSS.

- It was concluded that both sigma phase amount and chloride concentration worsen the pitting potential. The higher sigma content, the lower pitting potential and the higher chloride concentration, the lower pitting potential.

- Pitting nucleates preferentially at sigma phase interfaces for the aged specimens due to the development of Cr- and Mo-depleted zones around the sigma phase, formed by secondary ferrite and by secondary austenite.

- Hardness is not a sensitive parameter for low amounts of sigma phase. Hardness is significantly affected by higher sigma phase content.

\section{References}

[1] M. E. Arikan, R. Arikan, M. Doruk: International Journal of Corrosion, Vol. 2012, 2012, p. 1-10, DOI: 10.1155/2012/651829

[2] S.K. Ghosh, S. Mondal: Materials Characterization, Vol. 59, 2008; No. 12, p. 1776-1783, DOI:10.1016/j.matchar.2008.04.008

[3] K. L. Weng, T. H. Chen, J. R. Yang: Bulletin of the College of Engineering, N.T.U, Vol. 89, 2003, p. 45-61

[4] P. Paulraj, R. Garg: Advances in Science and Technology Research Journal, Vol. 9, 2009, No. 27, p. 87-105, DOI: 10.12913/22998624/59090

[5] R. T. Loto: Journal of Materials Research and Technology, Vol. 6, 2017, No.3, p. 203-212, DOI: $10.1016 /$ j.jmrt.2016.11.001

[6] H. M. Ezuber, A. El-Houd, F. El-Shawesh: Desalination, Vol. 207, 2007, p. 268-275, DOI:10.1016/j.desal.2006.05.021

[7] K. W. Chan, S. C. Tjong: Materials, 2014, Vol. 7, p. 5268-5304, DOI: 10.3390/ma7075268

[8] I. Calliari, M. Breda, E. Ramous, M. Magrini, G. Straffelini: Effect of isothermal heat treatments on Duplex Stainless Steels impact toughness, In: Convegno Nazionale IGF XXII, 1-3 Luglio, Roma, Italia, 2013, p. 56-65

[9] The American Society of Mechanical Engineers, ASME B31.3, ASME Code for Pressure Piping, B31.3 - 2004

[10]H. Keshmiri, A. Momeni, K. Dehghani, G. R. Ebrahimi, G. Heidari: Journal of Materials Science \& Technology, Vol. 25, 2009, No. 5, p. 597-602

[11]T. Mathiesen, C. Jensen: Rapid Corrosion Test for Detecting Intermetallic Phases in Duplex Stainless Steels, In: NACE Corrosion 2013, Orlando, FL, Paper 02583, March 2013, p. 1-12

[12] I. J. Marques, A. A. Vicente, J. A. S. Tenório, T. F. A. Santos: Materials Research, Vol. 20, 2017, No. 2, p. 152-158, DOI: 10.1590/1980-5373-MR-2016-1060

[13] J. R. Saithala, S. Mahajanam, H. S. Ubhi, J. D. Atkinson: In: CORROSION 2012 Conference \& Expo- NACE, C2012-0001272, 2012 
[14] M. Martins, L. C. Casteletti: Material Characterization, Vol. 60, 2009, No. 2, p. 150-115, DOI: 10.1016/j.matchar.2008.12.010

[15] J. H. Potgieter: British Corrosion Journal, Vol. 27, 1992, No. 3, p. 219-223

[16] J. A. Castro, E. M Oliveira, D. S. S. Almeida, G. S. Fonseca, C. R. Xavier: Materials Research, Vol. 20, 2017, No. 1, p. 153-161, DOI: 10.1590/1980-5373-MR-2017-0384

[17]D. M. E. Villanueva, F. C. P. Junior, R. L. Plaut, A. F. Padilha: Materials Science and Technology, Vol. 22, 2006, No. 9, p. 1098-1104, DOI: 10.1179/174328406X109230

[18]C. Dong, H. Luo, K. Xiao, T. Sun, Q. Liu, X. Li: Journal of Wuhan University of Technology-Mater. Sci. Ed, Vol. 26, 2011, No. 4, p. 641-647, DOI: 10.1007/s11595-0110283-4

[19] N. Ebrahimi, M.H. Moayed, A. Davoodi: Corrosion Science, Vol. 53, 2011, No. 4, p. 1278-1287, DOI: 10.1016/j.corsci.2010.12.019

[20] ASTM A790: Standard Specification for Seamless and Welded Ferritic/Austenitic Stainless Steel Pipe, An American National Standard, 2000

[21]B. Deng, Z. Wang, Y. Jiang, H. Wang, J. Gao, J. Li : Electrochimica Acta, Vol. 54, 2009, No. 10, p. 2790-2794, DOI: 10.1016/j.electacta.2008.11.038

[22] J. Michalska, M. Sozańska: Materials Characterization, Vol. 56, 2006, No. 4, p. 355-362, DOI: 10.1016/j.matchar.2005.11.003

[23]R. Magnabosco: Materials Research, Vol. 12, 2009, No. 3, p. 321-327, DOI: 10.1590/S1516-14392009000300012

[24]C. C. Hsieh, W. Wu: ISRN Metallurgy, Vol. 2012, 2012, p. 1-16, DOI: 10.5402/2012/732471

[25]T.A. Palmer, J.W. Elmer, S.S. Babu, E.D. Specht: Direct Observations of Sigma Phase Growth and Dissolution in 2205 Duplex Stainless Steel, In: Trends in Welding Research, Pine Mountain, GA, United States, May 16, 2005 through May 20, 2005, p. 1-8

[26] R. Magnabosco, N. A. Falleiros: CORROSION, Vol. 61, 2005, No. 2, p. 130-136, DOI: $10.5006 / 1.3278167$

[27]D. C. Santos, R. Magnabosco, C. M. Neto: CORROSION, Vol. 69, 2013, No. 9, p. 900-911, DOI: $10.5006 / 0768$

[28] M. Pohl, O. Storz, T. Glogowski : Materials Characterization, Vol. 58, 2007, No. 1, p. 65-71, DOI: 10.1016/j.matchar.2006.03.015

[29]R. A. Akisanya, U. Obi, N. C. Renton: Materials Science and Engineering A, Vol. 535, 2012, p. 281-289, DOI: 10.1016/j.msea.2011.12.087

[30] R. Magnabosco, L. E. Oiye, C. K. Sutto : Microhardness of UNS S31803 (SAF 2205) duplex stainless steel after isothermal aging between $700^{\circ} \mathrm{C}$ and $900^{\circ} \mathrm{C}$, In: 17 th International Congress of Mechanical Engineering, São Paulo, November 10-14, 2003, p. $1-7$

[31] J. O. Nilsson, P. Kangas, T. Karlsson, A. Wilson: Metallurgical and Materials Transactions A, Vol. 31A, 2000, No. 1, p. 35-45, DOI: 10.1007/s11661-000-0050-1 